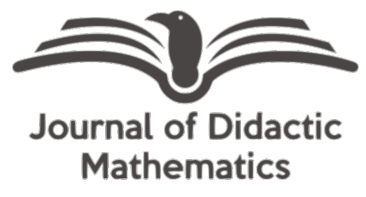

\title{
Kemampuan penalaran matematis mahasiswa berdasarkan variasi gender dan self-efficacy matematis
}

\section{Samsul Bahri*}

Universitas Nahdlatul Wathan, Mataram, Nusa Tenggara Barat, Indonesia, 82137

\section{Farah Heniati Santosa}

Universitas Nahdlatul Wathan, Mataram, Nusa Tenggara Barat, Indonesia, 82137

\section{Kiki Riska Ayu Kurniawati}

Universitas Islam Negeri, Mataram, Nusa Tenggara Barat, Indonesia, 83116

\section{Habibi Ratu Perwira Negara}

Universitas Islam Negeri, Mataram, Nusa Tenggara Barat, Indonesia, 83116

*Corresponding Author: samsulbahri024@gmail.com

\begin{abstract}
The purpose of this study was to determine the differences in mathematical reasoning ability (KPM) based on gender variation (VG) and mathematical self-efficacy (SEM). Quantitative research was chosen to answer the research question. The research design used comparative causality on 75 students at a State University in Mataram City. Data collection was based on gender variance in the selected sample (51 women and 24 men, KPM test scores consisting of 5 items, and a 20-point SEM questionnaire, which were further categorized into 3 levels (low, medium and high). Analysis The data used twoway ANOVA with a $3 \times 2$ factorial design. The post-anava follow-up test used the turkey test. The results showed that male KPM was better than female KPM. Based on SEM category, student KPM at high SEM was better than student KPM at low SEM This finding emphasizes the importance of instructors being able to observe the characteristics of self-efficacy and gender variations that have an impact on the mathematics learning process.
\end{abstract}

Historis Artikel:

Diterima: 21 Desember 2021

Direvisi: 4 Januari 2022

Disetujui: 10 Januari 2022

Keywords:

Mathematical reasoning ability; gender; mathematical self-efficacy

Sitasi: Bahri, S., Santosa, F. H., Kurniawati, K. R. A., \& Negara, H. R. P. (2021). Kemampuan penalaran matematis mahasiswa berdasarkan variasi gender dan self-efficacy matematis. Journal of Didactic Mathematics, 2(3), 134-141. Doi: $10.34007 /$ jdm.v2i3.1047

\section{PENDAHULUAN}

Proses pemahaman dan penyelesaian masalah tidak terlepas dari kemampuan penalaran (Anisah et al., 2011; Ismail et al., 2021; Tjalla, 2010). Melalui penalaran memungkinkan siswa dalam menemukan ide, sifat maupun metode dalam proses pemikiran logis dan saling terhubung, tidak hanya sekedar proses perhitungan rutinitas. Penalaran matematis menjadi suatu proses yang selalu berlangsung dalam pikiran yang harus dikembangkan secara konsisten dengan menggunakan berbagai konteks. Artinya, penalaran matematis adalah kemampuan menganalisis situasi matematis yang berlangsung, kemudian hasil proses analisis tersebut mencapai suatu kesimpulan yang konkrit (Angraini, 2020; Loc \& Uyen, 2014). Hal ini sesuai dengan pernyataan Amir-mofidi (2012) yang mendefinisikan penalaran sebagai proses penarikan kesimpulan logis berdasarkan bukti dan sumber. Sehingga, dapat dinyatakan bahwa kemampuan penalaran diperlukan untuk mencapai suatu kesimpulan berdasarkan informasi yang tersedia sebelum mengambil keputusan.

Beberapa penelitian tentang pentingnya kemampuan penalaran matematis telah dilakukan oleh (Jäder \& Sidenvall, 2016; Napitupulu, 2017; Napitupulu et al., 2016; Salmina \& Nisa, 2018). Penelitian tersebut menyatakan bahwa kemampuan penalaran matematis perlu dimiliki oleh siswa 
Kemampuan penalaran matematis mahasiswa berdasarkan variasi...

agar kemampuan berpikir siswa menjadi lebih baik. Namun, fakta terkait rendahnya kemampuan penelaran matematis siswa diungkap pada hasil evaluasi Trends in International Mathematics and Science Study (TIMSS). Hasil tersebut melaporkan bahwa, siswa Indonesia berada pada posisi 5 dari bawah (Puspendik (Pusat Penilaian Pendidikan), 2012, 2016; TIMSS, 2015). Hasil penelitian yang dilakukan oleh Ayuningtyas et al., (2019) dan Sandy et al., (2019), mengungkapkan kemampuan penalaran matematis siswa masih rendah. Hal ini mengindikasikan bahwa kemampuan penalaran menjadi penting untuk dikaji dan dikembangkan.

Dalam proses penalaran, terdapat faktor internal yang ikut mempengaruhi proses bernalar. Salah satunya adalah variasi gender. Variasi gender menjadi salah satu elemen yang mempengaruhi kemampuan penalaran matematis (Brandell \& Staberg, 2008; Mendick, 2005; Sumpter, 2014, 2015b). Kesenjangan variasi gender dalam matematika telah muncul saat anak-anak berkembang (Harris et al., 2020). Pada penelitian Erdem \& Soylu (2017), Siswa perempuan lebih cenderung menggunakan teknik yang diberikan kepada mereka oleh instruktur mereka, sedangkan siswa lakilaki merancang metode baru dan berpikir lebih abstrak. Berdasarkan kecenderungan dalam berpikir ini, variasi gender berdampak pada proses penalaran matematis siswa.

Faktor afektif menjadi salah satu faktor lain yang ikut mempengaruhi keberhasilan belajar matematika selain variasi gender. Salah satu bentuk aspek afektif adalah Self-efficacy matematis. Self-efficacy matematis didefinisikan sebagai keyakinan individu dalam kapasitas mereka untuk mengembangkan dan menerapkan program khusus untuk memecahkan masalah atau menyelesaikan proyek (Bandura, 1997; Schunk, 2012). Hal ini diperkuat dengan penelitian sebelumnya, bahwa self-efficacy matematis memiliki peran dalam keberhasilan siswa dengan tugas aritmatika (Karunika et al., 2019; Negara, 2021). Siswa dengan self-efficacy yang kuat akan membantu mereka menciptakan perasaan tenang dalam menghadapi masalah atau kegiatan yang sulit, sedangkan siswa dengan self-efficacy yang rendah akan segera menyerah dalam menghadapi masalah dan memiliki perspektif yang terbatas tentang cara terbaik untuk menangani masalah. Kondisi tersebut berdampak pula pada level Perguruan Tinggi, dimana pada level tersebut situasi belajar menjadi lebih kompleks. Mahasiswa dihadapkan dengan situasi belajar yang baru, materi pembelajaran yang lebih luas, serta kompetisi/persaingan antar mahasiswa menjadi lebih sulit. Hal ini diperkuat dengan hasil penelitian yang dilakukan oleh Negara (2021), yang menjelaskan bahwa terdapat korelasi postif self-efficacy matematis dengan kinerja matematika. Sehingga diduga selfefficacy matematis akan berdampak pada proses penalaran matematis siswa selain variasi gender.

Berdasarkan paparan di atas, tujuan penelitian adalah untuk mengetahui perbedaan kemampuan penalaran matematis berdasarkan variasi gender dan self-efficacy. Penelitian ini sebagai tindak lanjut pada penelitian sebelumnya (Negara, 2021) dan memperluas dari kajian yang telah dilakukan oleh (Salmina \& Nisa, 2018) dengan mengamati aspek self-efficacy matematis. sehingga, pertanyaan penelitian yang diajukan berupa: (1) apakah terdapat perbedaan kemampuan penalaran matematis berdasarkan variasi gender dan; (2) apakah terdapat perbedaan kemampuan penalaran matematis ditinjau dari self-efficacy matematis.

\section{METODE}

Peneliti memilih penelitian kuantitif untuk menjawab pertanyaan penelitian. Desain penelitian berupa kausal komparatif pada 75 orang mahasiswa (51 perempuan dan 24 laki-laki) pendidikan matematika pada salah satu Perguruan Tinggi Negeri di Kota Mataram. Teknik pengumpulan data menggunakan tes dan angket self-efficacy. Instrumen kemampuan penalaran matematis (KPM) terdiri dari 5 butir pada materi Triginometri. Adapun indikator kemampuan penalaran terdiri dari (1) Memorized Reasoning, (2) Algorithmic Reasoning, (3) Novelty, (4) Plausible, dan (5) Mathematical foundation. Contoh bentuk soal aspek penalaran yang diukur disajikan pada Tabel 1. 
Tabel 1. Indikator dan aspek yang diukur pada KPM

Indikator Aspek penalaran yang di ukur

\section{Soal}

Memorized Mahasiswa mampu

Reasoning mengingat, menerapkan

Mathematical Mahasiswa foundation menerapkan dan disertai argument yang logis terhadap penerapan konsep

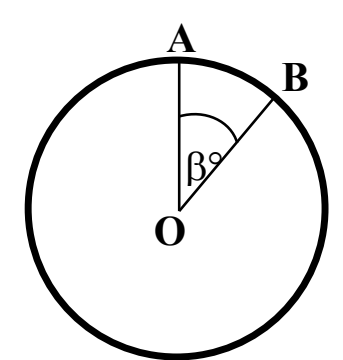

mampu Dua buah kapal $K$ dan $L$ berangkat pada waktu yang bersamaan dari pelabuhan $M$ dengan kecepatan yang konsep/prinsip dan strategi berbeda. Kapal $K$ berlayar ke arah selatan sejauh 20 pemecahan masalah yang $\mathrm{km}$, sedangkan kapal $L$ berlayar ke arah tenggara. relevan berkaitan dengan Setelah kapal $L$ berlayar beberapa kilometer, kapal trigonometri tersebut mengalami kerusakan teknis, sehingga kapal $K$ harus berbelok menjemput penumpang dari kapal $L$ sejauh $60^{\circ}$. Jarak yang ditempuh untuk menuju kapal $L$ sejauh $12 \mathrm{~km}$. Berapakah jarak yang sudah ditempuh kapal $L$ dari pelabuhan $M$ hingga mengalami kerusakan teknis?

Instrument self-efficacay matematis (SEM) berupa angket yang terdiri dari 20 butir soal yang telah dikembangkan oleh Negara (2021) yang telah disesuaikan dengan proses pembelajaran online, indikator dan contoh butir pernyataan angket SEM yang diukur disajikan pada Tabel 2.

Tabe1 2. Indikator dan aspek yang diukur pada SEM

\section{Indikator Aspek yang di ukur \\ Pernyataan}

Magnitude dimension Melihat tugas yang sulit Saya merasa putus asa dalam bekerja sebagai suatu tantangan menyelesaikan tugas Matematika secara online*

Strength dimension Percaya dan mengetahui Saya yakin bisa mempelajari konsep keunggulan yang dimiliki penting matematika yang diajarkan oleh dosen pada pembelajaran online ini

Generality dimension Menjadikan pengalaman yang Saya dapat menggunakan contoh atau lampau sebagai jalan untuk soal yang mirip untuk menyelesaikan mencapai keberhasilan masalah

\section{*ITEM Negatif}

Pengukuran SEM menggunakan scala likert 1-4, dimana skor terendah sebesar 20 dan skor tertinggi sebesar 80. Tabel 3 menunjukkan kategori SEM berdasarkan skor angket yang diperoleh. Hasil identifikasi self-efficacy matematis, dibedakan dalam 3 kategori yaitu SEM_rendah (25 orang); SEM_sedang (35 orang) dan; SEM_tinggi (15 orang). Analisis data menggunakan ANAVA dua jalur dengan desain factorial $3 \times 2$ dan uji lanjut menggunakan uji Tukey. Proses analisis dilakukan dengan bantuan SPSS 25.

Tabel 3. Kategori level SEM (Arifin, 2020)

$$
\begin{gathered}
\text { Rentang Skor } \\
20-40 \\
41-60 \\
61-80
\end{gathered}
$$

\section{Kategori}

Self-efficacy matematis Rendah Self-efficacy matematis Sedang Self-efficacy matematis Tinggi 
Kemampuan penalaran matematis mahasiswa berdasarkan variasi...

\section{HASIL DAN PEMBAHASAN}

Tujuan penelitian berupa memperoleh gambaran terkait perbedaan kemampuan penalaran matematis berdasarkan variasi gender dan self-efficacy matematis. Hasil analisis secara deskriptif kemampuan penalaran matematis berdasarkan variasi gender (VG) dan self-efficacay disajikan pada Tabel 4 dibawah ini.

Tabel 4. Skor KPM berdasarkan VG dan SEM

\begin{tabular}{rlrrr}
\hline \multicolumn{1}{c}{ VG } & \multicolumn{1}{c}{ SEM } & Mean & Std. Deaviation & N \\
\hline \multirow{7}{*}{ Perempuan } & Rendah & 57.8000 & 8.14336 & 15 \\
& Sedang & 63.4074 & 6.81773 & 27 \\
& Tinggi & 67.0000 & 4.63681 & 9 \\
\multirow{3}{*}{ Laki-laki } & Total & 62.3922 & 7.54209 & 51 \\
& Rendah & 65.3000 & 3.71334 & 10 \\
& Sedang & 67.7500 & 7.18630 & 8 \\
& Tinggi & 71.3333 & 2.16025 & 6 \\
Total & Total & 67.6250 & 5.29817 & 24 \\
& Rendah & 60.8000 & 7.61030 & 25 \\
& Sedang & 64.4000 & 7.04273 & 35 \\
& Tinggi & 68.7333 & 4.33370 & 15 \\
& Total & 64.0667 & 7.29371 & 75 \\
\hline
\end{tabular}

Tabel 4 merincikan kemampuan penalaran matematis yang diperoleh mahasiswa. Berdasarkan VG, perempuan berjumlah 51 orang $(M=62.3922 ; S D=7.54209)$ dan Laki-laki berjumlah 24 orang $(M=67.6250 ; S D=5.29817)$. Sedangkan dilihat berdasarkan SEM, sebanyak 25 orang berkategori SEM_Rendah $(M=60.8 ; S D=7.6103)$, sebanyak 35 orang berkategori SEM sedang $(M=64.4$; $S D=7.04273)$, dan sebanyak 15 orang berkategori SEM tinggi $(M=68.7333$; $S D=4.33370)$

Selanjutnya, untuk menjawab pertanyaan penelitian, analisis ANAVA dua jalan diterapkan dengan bantuan SPSS 25. Adapun hasil analisis disajikan pada Tabel 5 sebagai berikut.

Tabel 5. Analisis KPM berdasarkan VG dan SEM

\begin{tabular}{lrrrrr}
\hline Source & Type III Sum of Squares & df & Mean Square & \multicolumn{1}{c}{ F } & Sig. \\
\hline Corrected Model & $1118.815^{\mathrm{a}}$ & 5 & 223.763 & 5.479 & .000 \\
Intercept & 254133.876 & 1 & 254133.876 & 6222.910 & .000 \\
VG & 431.440 & 1 & 431.440 & 10.565 & .002 \\
SEM & 542.778 & 2 & 271.389 & 6.645 & .002 \\
VG ${ }^{*}$ SEM & 37.140 & 2 & 18.570 & .455 & .637 \\
Error & 2817.852 & 69 & 40.838 & & \\
Total & 311777.000 & 75 & & & \\
Corrected Total & 3936.667 & 74 & & & \\
\hline
\end{tabular}

Berdasarkan Tabel 5, Nilai signifikansi pada bagian Corrected Model dapat digunakan untuk menilai pengaruh SEM siswa dan variasi gender terhadap KPM yang diterima siswa secara bersamaan. Hasil diperoleh $F(5,69)=5.479 ; p<.05$ yang disimpulkan $\mathrm{H}_{0}$ ditolak. Akibatnya, pada tingkat kepercayaan 95\%, dimungkinkan untuk menyimpulkan bahwa siswa SEM dan perbedaan gender memiliki pengaruh terhadap KPM yang dicapai siswa (Harris et al., 2020; Karunika et al., 2019; Negara, 2021).

Selanjutnya pada baris VG, diperoleh $F(1,69)=10.565 ; p<.05$ yang disimpulkan $\mathrm{H}_{0}$ ditolak. Sehingga terdapat perbedaan kemampuan penalaran matematis berdasarkan variasi gender. Karakteristik pola berpikir antara perempuan dan laki-laki telah menjadi faktor dalam matematika 
sejak anak-anak berkembang, hal ini pun berkontribusi pada proses penalaran matematis. Disparitas gender dalam taktik pembelajaran berkontribusi pada perbedaan dalam proses penalaran matematis (Kadarisma et al., 2019; Marzuki et al., 2020; Wolbers \& Hegarty, 2010). Siswa laki-laki lebih suka menggunakan perhitungan metrik dan fokus pada aspek terpenting dari studi mereka, sedangkan siswa perempuan memilih untuk menggunakan strategi tradisional dan terkenal (Ruggiero et al., 2008; Wolbers \& Hegarty, 2010). Siswa perempuan lebih cenderung menggunakan teknik yang diberikan kepada mereka oleh instruktur mereka, sedangkan siswa laki-laki merancang metode baru dan berpikir lebih abstrak (Erdem \& Soylu, 2017). Siswa perempuan melakukan perhitungan penjumlahan dan pengurangan dengan jari mereka, sedangkan siswa laki-laki menggunakan perhitungan mental (Carr \& Davis, 2001). Siswa laki-laki mengeksplorasi berbagai pilihan dalam pemikiran mereka dan, sebagai hasilnya, menggunakan sejumlah strategi (Sumpter, 2015a). Berdasarkan skor KPM (lihat Tabel 4) terlihat bahwa rerata kemampuan penalaran matematis perempuan sebesar 62.3922 jauh berbeda dengan rerata kemampuan penalaran matematis yang dipeorleh laki-laki sebesar 67.6250. Sehingga penelitian ini, memperkuat pernyataan temuan penelitian-penelitian sebelumnya (Kadarisma et al., 2019; Marzuki et al., 2020; Wolbers \& Hegarty, 2010).

Pada baris SEM, diperoleh $F(2,69)=6.645 ; p<.05$ (lihat Tabel 5) yang berarti bahwa $\mathrm{H}_{0}$ ditolak. Hasil ini menjelaskan bahwa pada kategori SEM terdapat perbedaan kemampuan penalaran matematis. Analisis selanjutnya, berupa uji Tukey untuk menyelidiki lebih lanjut terkait perbedaan kemampuan penalaran matematis berdasarkan SEM. Adapun hasil uji Tukey disajikan pada Tabel 6 sebagai berikut.

Tabel 6. Komparasi KPM berdasarkan SEM

\begin{tabular}{clrrr}
\hline \multicolumn{1}{c}{$(\mathrm{I})$ SEM } & (J) SEM & Mean Difference $(\mathrm{I}-\mathrm{J})$ & Std. Error & \multicolumn{1}{c}{ Sig. } \\
\hline \multirow{2}{*}{ Rendah } & Sedang & -3.6000 & 1.67342 & .087 \\
& Tinggi & $-7.9333^{*}$ & 2.08713 & .001 \\
Sedang & Rendah & 3.6000 & 1.67342 & .087 \\
& Tinggi & -4.3333 & 1.97215 & .079 \\
Tinggi & Rendah & $7.9333^{*}$ & 2.08713 & .001 \\
& Sedang & 4.3333 & 1.97215 & .079 \\
\hline
\end{tabular}

Hasil Tabel 6, menunjukkan bahwa tidak terdapat perbedaan KPM antara SEM rendah dengan SEM sedang $(p>$.05). Hasil yang sama pada ketegori SEM sedang dan SEM tinggi memiliki perbedaan KPM yang tidak signifikan $(p>$.05). Hasil ini diperkuat pada rerata KPM pada SEM sedang sebesar 64.4 (lihat Tabel 4) tidak lebih baik dibandingkan dengan rerata KPM pada SEM rendah $(60,8)$. Begitu pula pada skor KPM tinggi (68.73) tidak lebih baik dibandingkan dengan skor KPM sedang (64.4). Temuan ini sedikit berbeda pada hasil temuan yang dilakukan oleh (Ma, 2021; Schöber et al., 2018), yang menjelaskan bahwa siswa yang memiliki SEM yang lebih tinggi memiliki kemampuan akademik yang lebih baik dibandingkan siswa pada SEM yang berada di bawahnya. Namun perbedaan temuan ini, dapat menjadi dasar baru pada penelitian selanjutnya, bahwa pada kondisi tertentu, kemampuan matematis pada kategori SEM yang berdekatan yaitu SEM rendah dan SEM sedang atau SEM sedang dan SEM tinggi memiliki kemampuan yang tidak jauh berbeda.

Beralih pada perbandingan antara kategori SEM rendah dan SEM tinggi. Berdasarkan Tabel 6 disimpulkan bahwa terdapat perbedaan yang signifikan $(\phi<.05)$, yaitu KPM pada SEM tinggi lebih baik $(68,73)$ dibandingkan dengan KPM pada SEM rendah. Temuan ini memperkuat hasil temuan Schöber et al. (2018) dan Yelorda et al. (2021), dimana pada kategori SEM yang lebih tinggi dapat memiliki prestasi akademik yang lebih baik dibandingkan dengan kategori SEM yang lebih rendah. Pemberdayaan self-efficacy matematis merupakan upaya untuk meningkatkan kualitas pembelajaran. Menurut temuan penelitian ini, salah satu unsur yang mempengaruhi efektivitas pembelajaran matematika adalah aspek afektif berupa self-efficacy matematis (Kasturi et al., 2021; 
Kemampuan penalaran matematis mahasiswa berdasarkan variasi...

Zeldin et al., 2008). Temuan ini menekankan kepada instruktur, baik guru, dosen maupun orang tua bahwa pentingnya mengamati karakteristik self-efficacy yang berdampak pada proses pembelajaran matematika.

\section{KESIMPULAN}

Berdasarkan paparan di atas, diperoleh bahwa, terdapat perbedaan kemampuan penalaran matematis berdasarkan variasi gender, dimana laki-laki memiliki kemampuan penalaran matematis yang lebih baik dibandingkan dengan kemampuan penalaran matematis perempuan. Sedangkan berdasarkan kategori self-efficacy matematis, mahasiswa yang memiliki self-efficacy tinggi memiliki kemampuan penalaran matematis yang lebih bagus dibandingakan self-efficacy rendah. Temuan juga menjelaskan bahwa tidak ada perbedaan yang signifikan antara self-efficacy matematis yang berdekatan yaitu self-efficacy matematis rendah dengan self-efficacy matematis sedang dan selfefficacy sedang dengan self-efficacy matematis tinggi. seperti halnya penelitian lainnya, penelitian ini pun memiliki terbatas. Sampel penelitian yang dipeorleh dibatasi pada mahasiswa semester II yang berada pada salah satu Perguruan Tinggi Negeri di Kota Mataram, sehingga perluasan sampel diharapkan dapat mengeneralisasikan temuan.

\section{DAFTAR PUSTAKA}

Amir-mofidi, S. (2012). Instruction of mathematical concepts through analogical reasoning skills. Indian Journal of Science and Technology, 5(6), 2916-2922.

Angraini, L. M. (2020). Didactical design of mathematical reasoning in mathematical basic concepts of courses. JNPM Jurnal Nasional Pendidikan Matematika), 5(1), 1-12. http://dx.doi.org/10.33603/inpm.v5i1.3943

Anisah, A., Zulkardi, Z., \& Darmawijoyo, D. (2011). Pengembangan soal matematika model pisa pada konten quantity untuk mengukur. Jurnal Pendidikan Matematika, 5(1). https://doi.org/10.22342/jpm.5.1.333.

Arifin, S. (2020). Peningkatan kemampuan pemahaman dan penalaran matematis siswa yang memperoleh pembelajarand dengan model CGGD berbasis sosiokultural ditinjau dari level self-efficacy. Disertasi Doktor pada Sekolah Pascasarjana UPI Bandung. http://repository.upi.edu/57935/

Ayuningtyas, W., Mardiyana, \& Pramudya, I. (2019). Analysis of student' s geometry reasoning ability at senior high school. Journal of Physics: Conference Series, 1188, 012016. https://doi.org/10.1088/1742-6596/1188/1/012016

Bandura, A. (1997). Self-efficacy: The exercise of control. W.H. Freeman and Company.

Brandell, G., \& Staberg, E. (2008). Mathematics: a female, male or gender-neutral domain? A study of attitudes among students at secondary level. Gender and Education, 20(5), 495-509. https://doi.org/10.1080/09540250701805771

Carr, M., \& Davis, H. (2001). Gender differences in arithmetic strategy use: A function of skill and preference. Contemporary Educational Psychology, 26(3), 330-347. https://doi.org/10.1006/ceps.2000.1059

Erdem, E., \& Soylu, Y. (2017). Age and gender-related change in mathematical reasoning ability and some educational suggestions. Journal of Education and Practice, 8(7), 116-127. https://eric.ed.gov/?id=EJ1137539

Harris, D., Lowrie, T., Logan, T., \& Hegarty, M. (2020). Spatial reasoning, mathematics, and gender: Do spatial constructs differ in their contribution to performance?. British Journal of Educational Psychology, 91(1), 1-33. https://doi.org/10.1111/bjep.12371

Ismail, I., Nursalam, N., Angriani, A., \& Kusumayanti, A. (2021). Development of measurement tool for understanding, application, and reasoning mathematics of madrasah ibtidaiyah students. Kreano, Jurnal Matematika Kreatif-Inovatif, 12(1), 26-38. https://doi.org/10.15294/kreano.v12i1.27053 
Jäder, J., \& Sidenvall, J. (2016). Students' mathematical reasoning and beliefs in non-routine task solving. International Journal of Science and Mathematics Education, 15(4), 759-776. https://doi.org/10.1007/s10763-016-9712-3

Kadarisma, G., Nurjaman, A., Sari, I. P., \& Amelia, R. (2019). Gender and mathematical reasoning ability. Journal of Physics: Conference Series, 1157(4), 042109. https://doi.org/10.1088/17426596/1157/4/042109

Karunika, A. M., Kusmayadi, T. A., \& Fitrana, L. (2019). Profile of mathematical reasoning ability of female students based on self-efficacy. Journal of Physics: Conference Series, 1265, 012008. https://doi.org/10.1088/1742-6596/1265/1/012008

Kasturi, K., Sulton, S., \& Wedi, A. (2021). How self-efficacy in mathematic based on gender perspective?. Edcomtech: Jurnal Kajian Teknologi Pendidikan, 6(1), 36-45. https://doi.org/http://dx.doi.org/10.17977/um039v6i12021p036

Loc, N. P., \& Uyen, B. P. (2014). Using analogy in teaching mathematics: An investigation of mathematics education students in School of Education - Can Tho University. International Journal of Education and Research, 2(7), 91-98.

Ma, Y. (2021). A cross-cultural study of student self-efficacy profiles and the associated predictors and outcomes using a multigroup latent profile analysis. Studies in Educational Evaluation, 71(December 2020), 101071. https://doi.org/10.1016/i.stueduc.2021.101071

Marzuki, M., Cahya, E., \& Wahyudin. (2020). Relationship between mathematical creative thinking ability and student's achievement in gender perspective. Journal of Physics: Conference Series, 1521, 032039. https://doi.org/10.1088/1742-6596/1521/3/032039

Mendick, H. (2005). A beautiful myth? The gendering of being/doing 'good at maths'. Gender and Education, 17(2), 203-219. https://doi.org/10.1080/0954025042000301465

Napitupulu, E. E. (2017). Analyzing the teaching and learning of mathematical reasoning skills in Secondary School. Asian Social Science, 13(12), 167-173. https://doi.org/10.5539/ass.v13n12p167

Napitupulu, E. E., Suryadi, D., \& Kusumah, Y. S. (2016). Cultivating upper secondary students' mathematical reasoning-ability and attitude towards mathematics through problem-based learning. Journal on Mathematics Education, 7(2), 117-128.

Negara, H. R. P., Nurlaelah, E., Wahyudin, W., Hermat, T., \& Tamur, M. (2021). Mathematics self efficacy and mathematics performance in online learning. Journal of Physics.: Conference Series, 1882, 012050. https://doi.org/10.1088/1742-6596/1882/1/012050

Puspendik (Pusat Penilaian Pendidikan). (2012). Kemampuan matematika siswa SMP Indonesia menurut bechmark internasional TIMSS 2011. Jakarta: Balitbang Kemendikbud.

Puspendik (Pusat Penilaian Pendidikan). (2016). Kemampuan matematika siswa SMP Indonesia menurut bechmark internasional TIMSS 2015. Jakarta: Balitbang Kemendikbud.

Ruggiero, G., Sergi, I., Iachini, T., Ruggiero, G., Sergi, I., \& Iachini, T. (2008). Gender differences in remembering and inferring spatial distances. Memory, 16(8), 821-835. https://doi.org/10.1080/09658210802307695

Salmina, M., \& Nisa, S. K. (2018). Kemampuan penalaran matematis siswa berdasarkan gender pada materi geometri. Jurnal Numeracy, 5(1), 41-48.

Sandy, W. R., Inganah, S., \& Jamil, A. F. (2019). The analysis of students' mathematical reasoning ability in completing mathematical problems on geometry. Mathematics Education Journals, 3(1), 72-79.

Schöber, C., Schütte, K., Köller, O., McElvany, N., \& Gebauer, M. M. (2018). Reciprocal effects between self-efficacy and achievement in mathematics and reading. Learning and Individual Differences, 63(January 2017), 1-11. https://doi.org/10.1016/j.lindif.2018.01.008

Schunk, D. H. (2012). Learning theories: An educational perspective (Teori-teori pembelajaran: Perspektif pendidikan). Edisi Keenam Penerjemah: Eva Hamdiah, Rahmat Fajar. Yogyakarta: Pustaka Pelajar. 
Kemampuan penalaran matematis mahasiswa berdasarkan variasi...

Sumpter, L. (2014). Upper secondary school students' gendered conceptions about affect in mathematics. Nordic Studies in Mathematics Education, 17(2), 27-47.

Sumpter, L. (2015a). 'Boys press all the buttons and hope it will help': Upper secondary school teachers' gendered conceptions about students' mathematical reasoning. International Journal of Science and Mathematics Education, 14(8), 1535-1552. https://doi.org/10.1007/s10763-015$\underline{9660-3}$

Sumpter, L. (2015b). Investigating upper secondary school teachers' conceptions: Is mathematical reasoning considered gendered?. International Journal of Science and Mathematics Education, 14, 347-362. https://doi.org/10.1007/s10763-015-9634-5

TIMSS. (2015). Pusat penilaian pendidikan badan penelitian dan pengembangan. Jakarta: Balitbang.

Tjalla, A. (2010). Potret mutu pendidikan indonesia ditinjau dari hasil-hasil studi internasional. UT.

Wolbers, T., \& Hegarty, M. (2010). What determines our navigational abilities?. Trends in Cognitive Sciences, 14(3), 138-146. https://doi.org/10.1016/j.tics.2010.01.001

Yelorda, K., Bidwell, S., Fu, S., Miller, M. O., Merrell, S. B., Koshy, S., \& Morris, A. M. (2021). Self-efficacy toward a healthcare career among minority high school students in a surgical pipeline program: A mixed methods study. Journal of Surgical Education, 78(6), 1896-1904. https://doi.org/10.1016/j.jsurg.2021.04.010

Zeldin, A. L., Britner, S. L., \& Pajares, F. (2008). A comparative study of the self-efficacy beliefs of successful men and women in mathematics, science, and technology careers. Journal of Research in Science Teaching, 45(9), 1036-1058. https://doi.org/10.1002/tea.20195 